\title{
Sexuality and Reproductive Health Counseling in Adolescent Renal Transplant Recipients
}

\author{
Isa F. Ashoor ${ }^{*}, 1$ and Ryan H. Pasternak ${ }^{2}$ \\ ${ }^{I}$ Children's Hospital of New Orleans, LA, USA \\ ${ }^{2}$ Louisiana Health Sciences Center and Children's Hospital of New Orleans, LA, USA
}

\begin{abstract}
Normal adolescence marks a period of significant physical, cognitive and psychosocial change. It is characterized by transition from concrete to abstract thought processes and concern for risk taking behaviors. Adolescents and young adults with chronic conditions are at a particular disadvantage and tend to be more vulnerable to risky behavior than their healthy peers.

While there currently exists no information on the burden of sexually transmitted infections (STIs) in adolescent renal transplant recipients, they present a particularly worrisome population as they are likely to engage in risk taking behavior when they feel "normal" following transplantation to compensate for poor quality of life endured on dialysis. This is further compounded by adolescents' false perception that they are unlikely to acquire such infections, and the likely improvement in libido and sexual functioning after transplantation. The potential for acquiring a sexually transmitted infection is concerning given their immunocompromised status, and complex treatment regimens which might have unfavorable interactions with STI treatments.

Also, unintentional pregnancy is likely to have a significant impact on their overall medical condition and social functioning thereby impacting their long term allograft outcomes. As the pediatric nephrologist assumes a primary care provider role for these patients following their renal transplant, it becomes increasingly important to be familiar with basic reproductive health counseling techniques and available contraceptive methods on the market. Until consensus guidelines and specific recommendations for reproductive health counseling are developed for adolescent renal transplant recipients, this review provides a brief summary of available knowledge in those areas.
\end{abstract}

Keywords: Adolescence, contraception, counseling, kidney transplant, sexuality, sexually transmitted infections.

\section{INTRODUCTION}

For many children with end stage renal disease, the pediatric nephrologist becomes the primary care provider for their general health needs $[1,2]$. As children progress through puberty and enter adolescence they undergo significant physical, cognitive and psychosocial changes including decreased impulse control, which may lead to increased risk taking behaviors. During middle adolescence (ages 14-16 years) issues of sexuality and intimate relationships become more relevant to the adolescents' identity [3]. A basic understanding of adolescent sexuality and ability to provide confidential reproductive health counseling to this population could foster trust with the adolescent during a time period when they're most vulnerable to poor allograft outcomes [4].

\section{ADOLESCENTS AND RISK TAKING BEHAVIOR}

Normal adolescence marks a period of significant psychosocial change during which adolescents establish their identity. It is characterized by a transition from concrete to

*Address correspondence to this author at the Children's Hospital of New Orleans, 200 Henry Clay Avenue, New Orleans, LA 70118, USA;

Tel: 504-896-9238; Fax: 504-896-9240; E-mail: iashoor@chnola.org abstract thought and experimentation, decreased impulse control and increase in risk-taking behaviors. Examples of such behaviors include substance use, and unplanned or unprotected sexual activity [3]. This is further compounded by adolescents' perceived sense of invulnerability. Taylor and Nsuami surveyed 3336 students participating in the New Orleans school-based screening for STIs and found that $64.5 \%$ of participants did not consider themselves at high risk of STI [5]. This is particularly interesting as the rates of chlamydial and gonorrheal infections in this group were similar to the remaining $35.5 \%$ who considered themselves at high risk. Similar findings have been reported by other authors $[6,7]$.

Children with chronic conditions and disabilities may be more likely to engage in high-risk behaviors compared to their healthy counterparts $[8,9]$. Many of these children may have had delayed onset of puberty [10], and as such have witnessed their healthy counterparts engaging in risky activities while they have been limited in their activities or experiences. Once they gain some independence as they enter adolescence they may try to "catch-up" with their healthy peers by indulging in high-risk activities. The prevalence of co-morbid emotional and psychiatric conditions is also higher in children with chronic conditions [8]. Some may resort to substance use as a result of 
maladaptive coping mechanisms leading to other high-risk activity [11, 12]. Tinderberg et al. looked at the influence of protective factors in limiting adolescents' engagement in high risk activities [9]. They evaluated 7 protective factors on the personal, family and community levels. Examples of such factors include having an optimistic view of the future, finding it easy to talk to one or both parents about difficult matters, and passing all school subjects. Youth with 0-3 protective factors had 6.3 times higher odds of involvement in risky behaviors as opposed to healthy youth with 4 or more protective factors. When youth with chronic conditions had a similar number of protective factors to their healthy counterparts their odds remained higher at $1.3(95 \%$ CI 1 2.5).

\section{SEXUAL FUNCTION IN CHRONIC KIDNEY DISEASE}

Adolescent renal transplant recipients' risk is further compounded by changes in sexual function as they transition from dialysis to the post-transplant period. While there have been no pediatric studies addressing sexual dysfunction in this population, it has been well documented that both men and women suffer from sexual dysfunction in the setting of end stage renal disease [13-16]. Sexual dysfunction in ESRD encompasses a spectrum of conditions including hypoactive desire to have sex, sexual aversion, inhibited male orgasm, erectile dysfunction and female sexual arousal disorder [16]. Some entities may be due to organic pathology related to the etiology of renal disease or the biochemical and endocrinologic alterations associated with renal failure [17]. Others are related to emotional maladjustment to the chronic disease process [18]. Everaerd et al. looked at these different forms of sexual dysfunction across the modalities of ESRD treatment. Their findings were notable for higher rates of loss of sexual desire in both men and women on dialysis compared to transplant recipients [16]. Renal transplantation has also been shown to objectively improve erectile function though not all patients will achieve pre-uremic function [19]. Einollahi et al. compared sexual functioning in kidney transplant recipients and hemodialysis male patients using a standardized relationship and sexuality scale and found an overall better sexual relationship, higher sexual frequency, better sexual function and less sexual fear in the transplant group [20]. Using a similar approach, Karami et al. found similar findings in a female cohort of hemodialysis patients and transplant recipients [21]. While the previous studies may be limited by their cross-sectional design and survey approach, Nicita et al. [14] embarked on a prospective study of 58 women who received a kidney transplant and demonstrated improvement of sexual life after successful transplantation. In their study, the rate of menstrual problems dropped from $74 \%$ to $45 \%$ after transplantation and the percentage of women who acknowledged having an active sexual life increased from $41 \%$ on dialysis to $88 \%$ after transplantation. Some of these changes are likely related to improvement in the hormonal profile following transplant as demonstrated by several studies [14, 22-24]. Yadav et al. prospectively followed a group of men on hemodialysis who had elevated levels of gonadotropins and prolactin with subnormal testosterone levels, and demonstrated significant improvement in serum testosterone and normalization of the elevated gonadotropins and prolactin as early as 6 months following successful renal transplantation [22]. Ferraris et al. described comparable hormonal changes in pubertal girls with chronic renal failure where elevated gonadotropins and prolactin levels, along with a blunted response to gonadotropins all improved in those who received a kidney transplant [23]. Given that adolescents with ESRD are not likely to have other significant co-morbidities such as diabetes and cardiovascular disease relative to their adult counterparts, the potential improvements in sexual functioning may be more pronounced.

In addition to the inherent sense of invulnerability during adolescence, many renal transplant recipients may have misconceptions regarding their fertility potential. While no specific pediatric data is available, data from adult women in the reproductive age group (19-49 years) in this regard is concerning. Wu et el surveyed 183 women with solid organ transplants of whom 73 were renal transplant recipients and $44 \%$ were under the impression they cannot become pregnant after transplantation [25]. This false sense of security may encourage adolescents to engage in unprotected sex due to perceived lack of consequence, while in reality pregnancy has been well documented as early as a few months post transplantation [26].

Finally, the majority of adolescents with end stage renal disease have had to deal with chronic illness early in life, and most have no recollection of what it feels like to be "normal". Hence, unlike adults with end stage renal disease, adolescents typically rate themselves at very high values for quality of life (QOL) following transplantation and perceive themselves as close to full health [27]. Since sexual function has been shown as a significant determinant of overall QOL [20], it should be assumed that adolescents will engage in relationships post transplantation.

\section{SEXUALLY TRANSMITTED INFECTIONS: BURDEN, SCREENING, TREATMENT AND PREVENTION}

\section{Burden and Relevance to Clinical Practice}

While there currently exists no information on the burden of STIs in adolescent renal transplant recipients, it is well known that infections are a significant source of morbidity and mortality following renal transplantation. Additionally adolescents in the general population carry the greatest disease burden for STIs, especially female adolescents where 1 in 4 may be infected with an STI including Human Papillomavirus (HPV) [28].

Adolescent renal transplant recipients are at risk for the entire range of STIs similar to healthy adolescents. These include gonococcal infections, chlamydial infections, pelvic inflammatory disease, syphilis, trichomoniasis, HPV, pubic lice, genital herpes and HIV infection among others. In an internal cross-sectional review of 49 adolescent renal transplant recipients older than 13 years of age at our center, we found an STI prevalence of $30 \%$ detected on targeted screening for symptomatic patients over the past 5 years, as opposed to a $15 \%$ prevalence in the healthy adolescent clinic population where universal screening is performed. The prevalence was higher in sexually active girls compared to 
boys and the infections seen included all the previously mentioned conditions.

Acquiring an STI in a renal transplant recipient is concerning as the immunosuppression status may lead to a more fulminant presentation as seen with genital warts [29], or make it difficult to eradicate without prolonged treatment courses or alterations in the immunosuppression regimen [30]. STI treatment agents may have significant interactions with immunosuppressants metabolized by the hepatic cytochrome p450 pathways leading to complicated regimens and higher frequency of side effects. This is particularly the case with anti-retroviral therapy for HIV infection [31]. Failure to mount an inflammatory response secondary to immunosuppression may also lead to asymptomatic carriage as is commonly seen with chlamydia trachomatis infection [32]. Therefore a high index of suspicion is mandatory. Dedicating a portion of the transplant clinic visit for a confidential discussion with the adolescent on a periodic basis can be the first step towards identifying concerning symptoms for STIs that adolescents may not otherwise volunteer in the presence of their caregivers. Recurrent urinary tract infections in adolescent girls in the absence of structural urinary tract abnormalities or vesico-ureteral reflux and dysuria with a negative urine culture may be the only indication of an STI in the absence of more obvious symptoms such as vaginal discharge, penile discharge and genital skin lesions.

\section{Screening}

While the current practice patterns of pediatric nephrologists with regards to STI screening and treatment are not known, the benefits of providing routine STI screening for adolescent renal transplant recipients cannot be overstated. As mentioned earlier, reliance on adolescents' perception of STI risk to direct screening may be misleading, as many tend to underestimate their likelihood of having an STI or are asymptomatic $[5,32,33]$. This along with the inherent discomfort in discussing such sensitive issues may easily lead to missed diagnoses. While pediatric transplant recipients are expected to have a primary care provider many of these providers are not using preventive care visits to engage adolescents about sexual health and STI prevention or screening [34], further highlighting the need for STI screening at transplant clinic visits.

Current screening guidelines should be followed for all patients and if an STI is detected a full work-up for other concomitant STIs including syphilis and HIV should be undertaken if not already completed [35, 36]. Schwarz et al. studied a cohort of 75,273 adolescents who underwent STI screening for $\mathrm{C}$. trachomatis, $\mathrm{N}$. gonorrhea and syphilis as part of a school based screening program and found that those with an STI had a significantly increased risk of subsequent HIV infection [37].

\section{Treatment}

Once an STI is diagnosed, treatment should be started without delay. This is particularly relevant in adolescent girls with cervicitis to reduce the risk of progression to pelvic inflammatory disease and tubo-ovarian abscess [10]. Care has to be taken to protect the adolescents' confidentiality in discussing the results and intended treatment. The AAP, WHO and Society for Adolescent Health and Medicine support providing this care confidentially, because many adolescents desire treatment for sensitive issues without disclosure to parents or others and confidentiality assurances increase the likelihood adolescents will discuss sensitive issues with providers [38-40].

The Centers for Disease Control and Prevention (CDC) publishes treatment guideline for STIs that are updated on a periodic basis [36]. Table 1 summarizes the recommended treatments for the most commonly acquired STIs.

\section{Prevention}

Prevention against STIs in adolescents involves a multistep approach starting with counseling regarding safer sex practices, followed by inducing active immunity with immunization (Hepatitis B and Human Papillomavirus), and finally post-exposure treatment or prophylaxis and partner treatment $[36,41]$.

\section{Counseling}

The pediatric nephrology team has the unique advantage of having followed most adolescent renal transplant recipients since the onset of their renal disease, which may be as early as when they were born. This relationship should theoretically make it easier for adolescents to trust the pediatric nephrologist and be receptive to their counseling. A consistent approach where all adolescents receive counseling regarding safer sex practices and screening occurs as per U.S. Preventive Service Task Force (USPSTF) and CDC Guidelines is critical as it has been shown that providers are often wrong when it comes to predicting which of their patients is at risk or screen at risk patients inadequately [42]. Counseling should be provided in a non-judgmental, developmentally appropriate and confidential manner. Issues to be addressed should include the potential risks to the adolescent's overall health and allograft function in the event of an STI or unintentional pregnancy. Counseling should be a continuum that starts in the pre-transplant period and continues afterwards. Hill et al. [43, 44] have shown that earlier initiation of counseling and behavior intervention programs is significantly more likely to reduce the risk of early initiation of sexual activity, high-risk sexual activity, and unintentional pregnancy by age 18 compared to later intervention. Having formal written policies and educational materials in this regard can be also an easy method to standardize information delivery and remove any potential stigma perceived by patients or their caregivers if they felt they were specifically targeted. The transplant coordinator can play an instrumental role in the counseling process by providing a consistent message starting from the pretransplant period. Transplant coordinators can provide the information verbally in an informal discussion, as a didactic lecture to a group of transplant recipients, or as formal handouts included in the post-transplant educational folder. A partnership with a child psychologist or adolescent medicine specialist who attends renal transplant clinic visits can be very helpful in providing more specific counseling for difficult cases. 
Table 1. Recommended treatments for common STIs.

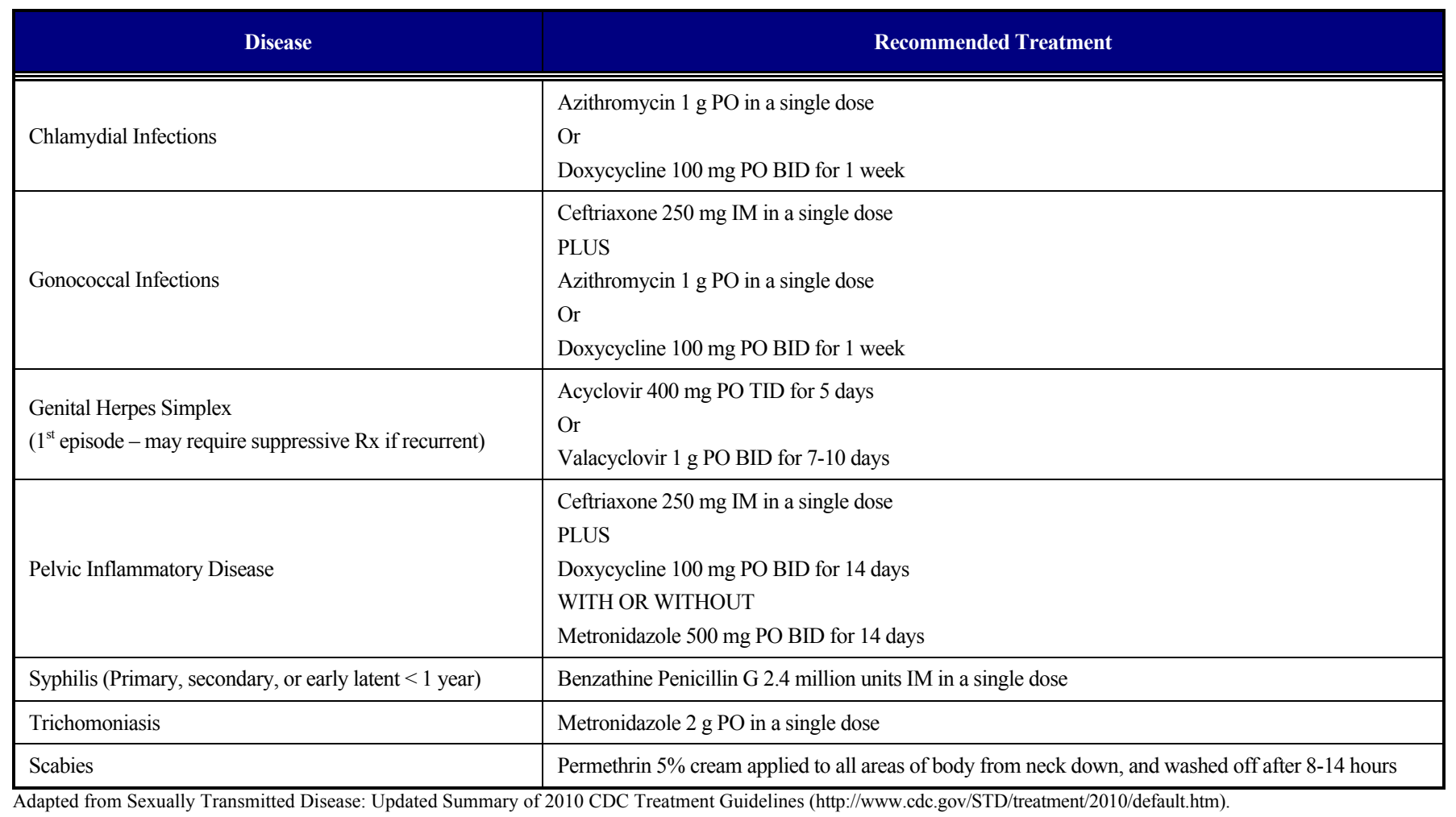

\section{Safer Sex}

While abstinence is the only definitive method of preventing STIs, it is imperative to provide information about other safer sex methods since a significant portion of adolescents will have had at least one sexual encounter by the age of 18 [45]. Providers should highlight consistent condom use as an effective method to reduce STI transmission risk. This is particularly important for females who may be on a hormonal contraceptive without realizing the added benefit of condoms for STI prevention. Free anonymous distribution of condoms in clinic can be an effective strategy in providing access to adolescents who may otherwise have limited access due to parental fear or financial constraints.

\section{Vaccination}

There are currently 2 FDA approved vaccinations against specific viral sexually transmitted infections. Hepatitis B vaccination has been on the market for years and most adolescents should have received the entire series before transplant as it's routinely completed during infancy. However, the antibody response to Hepatitis B vaccination may be suboptimal in patients with ESRD [46] necessitating monitoring of antibody titers to determine when revaccination is needed. More recently in 2006, the FDA approved Gardasil $\AA$, a recombinant vaccine against human papilloma virus (HPV) types 6, 11, 16 and 18 [47]. The CDC currently recommends routine vaccination with Gardasil ${ }^{\circledR}$ for girls and boys ages 11 to 12 . The serotypes included in the vaccine are responsible for about $75 \%$ of cervical cancer cases in females and about $90 \%$ of genital wart cases in both genders [47]. The prospect of using Gardasil \& for prevention is promising particularly since HPV-associated warts are a common occurrence in patients with chronic kidney disease [48] and may be resistant to standard topical therapy post transplantation [30]. Given the increased morbidity of HPV infection in immunocompromised individuals, the American College of Obstetricians and Gynecologists (ACOG) published exceptions to its Pap screening guideline in adolescents which now recommends screening six months apart after onset of sexual activity followed by annual screening in adolescent solid organ recipients [49].

\section{Post-Exposure Prophylaxis (PEP)}

PEP is available for individuals who had unprotected sex with an HIV positive person or someone whose serologic status is not known. Detailed recommendations are beyond the scope of this review and the reader is referred to http://aidsinfo.nih.gov/guidelines for specific recommendations [41]. In general, PEP should be started within 72 hours of exposure and the course lasts for 4 weeks. Patients should be referred to an infectious disease specialist and their immunosuppressant levels monitored closely given their interactions with anti-retroviral therapy.

\section{REPRODUCTIVE HEALTH COUNSELING: PREG- NANCY AND CONTRACEPTION METHODS}

Pregnancy is a realistic possibility in sexually active female adolescent renal transplant recipients. Many patients are under the false misconception that they are infertile secondary to their renal disease and immunosuppressive medications [25]. While pediatric data is not available, Wu et al. surveyed 183 solid organ recipient women aged 19-49 
years old and found that $44 \%$ did not realize a woman could become pregnant after transplantation [25]. This along with infrequent contraception counseling by their healthcare providers (36\% in the survey by $\mathrm{Wu}$ et al. [25] and 33\% in a similar survey by Wielgos et al. [50]) contributes to increased risk of unintentional pregnancy.

\section{Complications}

Patients who are planning to become pregnant are advised to wait for at least 1 year after transplant and to have a thorough medical assessment to ensure stable graft function, well controlled blood pressures, negligible proteinuria, and a safe medication regimen with the least possible side effects on the developing fetus [51]. They should be followed in a high-risk obstetric practice given the multitude of potential complications to both the expectant mother and fetus. These complications include but are not limited to the following: increased risk for miscarriage, stillbirth, preterm delivery, pre-eclampsia, low birth weight, intra-uterine growth restriction and congenital malformations $[10,26,51]$. The risk of congenital malformations in pregnant renal transplant recipients depends on the immunosuppression regimen taken in the 12 weeks leading to conception and maintained for the duration of pregnancy and can be as high as $20 \%$ in live born infants exposed to mycophenolate mofetil (MMF) as opposed to the general population risk of approximately $3 \%$ [52]. To account for the increased risk of congenital malformations, the FDA approved a risk evaluation and mitigation strategy (REMS) for mycophenolate mofetil prescription [53]. It is not yet known whether such a program has increased healthcare providers' counseling about reproductive health issues in general. Given that approximately $60 \%$ of all pediatric renal transplant recipients receive $\mathrm{MMF}$ as a long-term maintenance immunosuppressant [54], the MMF REMS program ensures provision of this basic reproductive health counseling to this population. The risk of congenital malformations with steroids, azathioprine and calcineurin inhibitors have only been found to be slightly higher or similar to the background risk in the general population with no specific recurring pattern of anomalies among live born fetuses $[55,56]$

\section{Contraceptive Methods}

The majority of unintended pregnancies occur in teens [57]. Therefore it is critical to provide all adolescent renal transplant recipients contraceptive counseling and offer all sexually active patients effective contraception. There are many contraceptive options available on the market, and the decision to use one over the other should be tailored for the individual patient. Several key factors have to be considered including efficacy, which also largely depends on convenient administration and therefore adherence, safety profile, and possible interactions with transplant medications. Contraceptive methods can largely be divided into barrier methods, intrauterine contraceptive devices (IUDs) and hormonal contraception. Table 2 briefly summarizes relevant points regarding these methods. Currently the American College of Obstetricians and Gynecologists (ACOG) recommend Long Acting Reversible Contraceptives or
LARC as the most effective and safest first line method for adolescents generally. LARC methods include intrauterine contraceptive devices (IUD) and implantable devices (etonogestrel implant) [58].

\section{Barrier Contraception}

Barrier methods include the male and female condoms, vaginal diaphragms and cervical caps. They are readily available over the counter and do not require a prescription. They do not interact with transplant medications and therefore are the safest contraceptive option. Condoms are also the only contraceptive method that, when used correctly and consistently, reduce the risk of STIs and as such many experts recommend using them as a second method when the primary contraceptive is a hormonal method or IUD [59]. Unfortunately, condom failure rates can be high for adolescents and can approach $20 \%$ depending on the user's experience [60]. Cervical caps and vaginal diaphragms can be cumbersome to insert limiting their acceptability to most adolescents.

\section{Intrauterine Contraceptive Devices}

IUDs are extremely effective and reversible contraceptive methods. 3 varieties are available on the market; the copper containing Paragard $\AA$ which can provide effective contraception for up to 10 years, and the levonorgestrel-releasing IUDs Skyla ${ }^{\circledR}$ and Mirena ${ }^{\circledR}$ which are effective for up to 3 and 5 years respectively. All have efficacies approaching $99 \%$ in healthy sexually active females. There have been theoretical concerns about reduced efficacy in the setting of chronic immunosuppression but there have been no documented cases of IUD failure in renal transplant recipients since 1981. IUDs have negligible interactions with transplant medications as the levonorgestrel systemic levels with Mirena ${ }^{\circledR}$ use are minimal [61]. There have been historical concerns for increased risk of pelvic and cervical infections with IUD use in immunosuppressed women [61], however, modern studies have discredited those concerns [62]. IUDs are now considered a very attractive contraceptive option, as their efficacy is not user-dependent.

\section{Hormonal Contraception}

Hormonal contraception can be broadly divided into combined estrogen and progestin preparations and progestin only preparations. Each comes in various delivery formats.

\section{Combined Estrogen and Progestin Methods}

The most frequently used combined estrogen and progestin contraceptive is the combined oral contraceptive pill (OCP). OCPs are highly effective if used consistently [63]. Given the additional pill burden and non-adherence risk, adolescents who choose this method should ideally use a barrier method as well. OCPs have been extensively studied in solid organ transplant recipients and are very safe $[61,64]$. They are contraindicated in patients with a history of deep venous thrombosis, uncontrolled hypertension, migraine with aura, and active liver disease due to the negative effect of the estrogen component [10]. In addition, OCPs inhibit the liver cytochrome P450 pathway potentially leading to increased systemic levels of tacrolimus, cyclosporine and sirolimus, which requires frequent 
Table 2. Summary of common contraceptive methods for adolescent renal transplant recipients.

\begin{tabular}{|c|c|c|c|}
\hline $\begin{array}{l}\text { Contraceptive } \\
\text { Method }\end{array}$ & Subtypes & Advantages & Disadvantages \\
\hline Barrier Methods & $\begin{array}{l}\text { Male and female condoms, } \\
\text { vaginal diaphragms and } \\
\text { cervical caps }\end{array}$ & $\begin{array}{l}\text { - } \\
\text { - } \text { Over the counter } \\
\text { - } \\
\begin{array}{l}\text { Offer STI protection (best for male } \\
\text { condom) }\end{array}\end{array}$ & $\begin{array}{l}\text { - Least effective contraception with high } \\
\text { failure rates } \\
\text { - Diaphragms and caps cumbersome to } \\
\text { insert }\end{array}$ \\
\hline $\begin{array}{l}\text { Intrauterine } \\
\text { Contraceptive } \\
\text { Device (IUD) }\end{array}$ & $\begin{array}{l}\text { Copper containing IUD } \\
\text { (Paragard } \AA \text { ) and } \\
\text { Levonorgestrel releasing IUD } \\
(\text { Mirena } \AA \text { and Skyla } \AA \text { ) }\end{array}$ & $\begin{array}{ll}\text { - } & \text { Very effective }(\sim 99 \%) \\
\text { - } & \text { Last 3-10 years } \\
\text { - } & \text { User independent }\end{array}$ & $\begin{array}{l}\text { - Requires an office procedure for } \\
\text { insertion } \\
\text { - Theoretical increased risk of cervical } \\
\text { and pelvic infections }\end{array}$ \\
\hline \multirow[t]{3}{*}{$\begin{array}{l}\text { Hormonal } \\
\text { Contraception }\end{array}$} & $\begin{array}{l}\text { Combined estrogen and } \\
\text { progestin methods: OCP, } \\
\text { transdermal patch, and } \\
\text { vaginal ring }\end{array}$ & $\begin{array}{l}\text { - Extensively studied in transplant recipients } \\
\text { - High efficacy if used consistently }(\sim 98 \%)\end{array}$ & $\begin{array}{l}\text { - User dependent } \\
\text { - Contraindicated with history of DVT, } \\
\text { uncontrolled hypertension, migraine } \\
\text { with aura and active liver disease } \\
\text { - OCPs interact with immunosuppressants } \\
\text { affecting systemic levels }\end{array}$ \\
\hline & $\begin{array}{l}\text { Progestin only methods: } \\
\text { mini-pill, DepoProvera } \AA \text {, } \\
\text { and Etonogestrel implant }\end{array}$ & $\begin{array}{l}\text { - Can be used if there is a contraindication to } \\
\text { estrogen } \\
\text { - } \quad \text { DepoProvera } \AA \text { and implant are highly } \\
\text { effective }(98-99 \%) \text { and user-independent }\end{array}$ & $\begin{array}{l}\text { - Mini-pill can have high failure rate if } \\
\text { inconsistent adherence } \\
\text { - Menstrual irregularities } \\
\text { - Reversible loss of bone mineral density } \\
\text { - Weight gain }\end{array}$ \\
\hline & Emergency Contraception & $\begin{array}{l}\text { - Effective up to } 5 \text { days after unprotected sex } \\
\text { - Progestin only formulation available over } \\
\text { the counter }\end{array}$ & $\begin{array}{l}\text { - Should not be a first line contraceptive } \\
\text { method }\end{array}$ \\
\hline
\end{tabular}

monitoring [10]. Combined hormonal contraception is also available in a transdermal delivery option with a patch applied three times per month and a vaginal ring applied once a month. Both methods overcome the necessity of daily administration and are less likely to interact with transplant medications $[65,66]$.

\section{Progestin Only Methods}

Progestin only hormonal contraception comes in the form of an oral pill (also referred to as the mini-pill), injectable intra-muscular preparation (Depo medroxyprogesterone acetate or DepoProvera ${ }^{\circledR}$ ) and subcutaneous implantable rods (Etonogestrel implant). They may be chosen based on efficacy, or used in women with contraindications to the estrogen component of combined hormonal contraceptives. The mini-pill is the least effective of the 3 delivery systems because of its user dependence, and is generally not recommended in adolescents [10]. The intramuscular formulation DepoProvera $\AA$ is extremely effective with 1 year failure rates of less than $2 \%$ in adults [67]. It is given every 12 weeks and most failures are related to delayed injections. There are no interactions with commonly used transplant medications. Major concerns regarding DepoProvera ${ }^{\circledR}$ use post-transplant include a tendency towards weight gain, and decreased, though reversible, bone mineral density [67]. The Etonogestrel implant is placed in the subcutaneous tissue of the upper arm and provides extremely effective contraceptive efficacy close to $99 \%$ for 3 years [68]. There are no studies regarding its use in renal transplant recipients though given the similarity to DepoProvera ${ }^{\circledR}$ it is assumed to have a similar benefit-risk profile.

\section{Emergency Contraception}

Whether by Yuzpe method (high/multi-dose COC), Oral Levonorgestrel (Plan B 1-Step B and similar), ulipristal acetate (Ella $(B)$, or copper IUD (Paragard $(B)$ refer to methods used after unprotected intercourse or contraceptive method failure (condom breakage, missed pills) to prevent pregnancy. Most methods have some effectiveness if taken up to 5 days after intercourse. Reported efficacy rates are as high as $85 \%$ [10] and all adolescents should be educated about the availability of this option. The FDA approved Plan B One Step progestin-only (levonorgestrel $1.5 \mathrm{mg}$ ) emergency contraception as an over the counter formulation without age restriction in June 2013 [69].

\section{CONCLUSION}

Adolescent renal transplant recipients are a vulnerable population as they navigate a developmental period intrinsically associated with risk-taking behavior along with significant changes in sexual function and quality of life following transplantation. The pediatric nephrologist has the unique opportunity to be the first line agent providing age appropriate reproductive health counseling and referral to other specialists when indicated. It is unreasonable to assume our adolescent patients will abstain from sexual activity, and lack of effective counseling could lead to dire consequences should they develop sexually transmitted infections or end up with unintentional pregnancy compromising their overall health and allograft outcome. Additional studies are needed to identify the current prevailing practice patterns in this field and direct the development of consensus guidelines for use by the pediatric transplant community. 


\section{CONFLICT OF INTEREST}

The authors confirm that this article content has no conflict of interest.

\section{ACKNOLWEDGEMENTS}

The authors would like to thank Dr. Matti V. Vehaskari for his review of the manuscript and constructive feedback.

\section{REFERENCES}

[1] Valderas JM, Starfield B, Forrest CB, Rajmil L, Roland M, Sibbald B. Routine care provided by specialists to children and adolescents in the United States (2002-2006). BMC Health Serv Res 2009; 9: 221.

[2] White CT, Trnka P, Matsell DG. Selected primary care issues and comorbidities in children who are on maintenance dialysis: a review for the pediatric nephrologist. Clin J Am Soc Nephrol 2007; 2(4): 847-57.

[3] Neinstein LGC, and Katzman D. Adolescent Healthcare: a Practical Guide. $5^{\text {th }}$ ed. 2008.

[4] Andreoni KA, Forbes R, Andreoni RM, Phillips G, Stewart H, Ferris M. Age-related kidney transplant outcomes: health disparities amplified in adolescence. JAMA Intern Med 2013; 173(16): 1524-32.

[5] Nsuami MJ, Taylor SN. Most adolescents who participate in school-based screenings for sexually transmitted infections do not perceive themselves at high risk of sexually transmitted infection. Int J STD Aids 2012; 23(11): 822-4.

[6] Abel G, Brunton C. Young people's use of condoms and their perceived vulnerability to sexually transmitted infections. Aust N Z J Public Health 2005; 29(3): 254-60.

[7] Ethier KA, Kershaw T, Niccolai L, Lewis JB, Ickovics JR. Adolescent women underestimate their susceptibility to sexually transmitted infections. Sex Transm Dis 2003; 79(5): 408-11.

[8] Bernert DJ, Ding K, Hoban MT. Sexual and substance use behaviors of college students with disabilities. AM J Health Behav 2012; 36(4): 459-71.

[9] Nylander C, Seidel C, Tindberg Y. The triply troubled teenager-chronic conditions associated with fewer protective factors and clustered risk behaviours. Acta Paediatr 2014; 103(2): 194-200.

[10] Sucato GS, Murray PJ. Gynecologic health care for the adolescent solid organ transplant recipient. Pediatr Tranplant 2005; 9(3): 34656.

[11] Wong CF, Silva K, Kecojevic A, et al. Coping and emotion regulation profiles as predictors of nonmedical prescription drug and illicit drug use among high-risk young adults. Drug Alcohol Depend 2013; 132(1-2): 165-71

[12] McConnell MM, Memetovic J, Richardson CG. Coping style and substance use intention and behavior patterns in a cohort of $\mathrm{BC}$ adolescents. Addict Behav 2014; 39(10): 1394-7.

[13] Basok EK, Atsu N, Rifaioglu MM, Kantarci G, Yildirim A, Tokuc R. Assessment of female sexual function and quality of life in predialysis, peritoneal dialysis, hemodialysis, and renal transplant patients. Int Urol Nephrol 2009; 41(3): 473-81.

[14] Filocamo MT, Zanazzi M, Li Marzi V, et al. Sexual dysfunction in women during dialysis and after renal transplantation. J Sex Med 2009; 6(11): 3125-31.

[15] Tavallaii SA, Mirzamani M, Heshmatzade Behzadi A, et al. Sexual function: a comparison between male renal transplant recipients and hemodialysis patients. J Sex Med 2009; 6(1): 142-8.

[16] Toorians AW, Janssen E, Laan E, et al. Chronic renal failure and sexual functioning: clinical status versus objectively assessed sexual response. Nephrol Dial Transplant 1997; 12(12): 2654-63.

[17] Burgos FJ, Pascual J, Gomez V, Orofino L, Liano F, Ortuno J. Effect of kidney transplantation and cyclosporine treatment on male sexual performance and hormonal profile: a prospective study. Transplant Proc 1997; 29(1-2): 227-8.

[18] Oyekcin DG, Gulpek D, Sahin EM, Mete L. Depression, anxiety, body image, sexual functioning, and dyadic adjustment associated with dialysis type in chronic renal failure. Int J Psychiat Med 2012; 43(3): $227-41$
[19] Hegarty PK, Olsburgh J. Renal replacement and male sexuality. Transplant Proc 2012; 44(6): 1804-5.

[20] Tavallaii SA, Fathi-Ashtiani A, Nasiri M, Assari S, Maleki P, Einollahi B. Correlation between sexual function and postrenal transplant quality of life: does gender matter? J Sex Med 2007; 4(6): 1610-8

[21] Noohi S, Azar M, Behzadi AH, et al. Comparison of sexual function in females receiving haemodialysis and after renal transplantation. J Ren Care 2010; 36(4): 212-7.

[22] Yadav R, Mehta SN, Kumar A, Guleria S, Seenu V, Tiwari SC. A prospective analysis of testicular androgenic function in recipients of a renal allograft. Int urol nephrol 2008; 40(2): 397-403.

[23] Ferraris JR, Domene HM, Escobar ME, Caletti MG, Ramirez JA, Rivarola MA. Hormonal profile in pubertal females with chronic renal failure: before and under haemodialysis and after renal transplantation. Acta Endocrinol 1987; 115(3): 289-96.

[24] Peces R, de la Torre M, Urra JM. Pituitary-testicular function in cyclosporin-treated renal transplant patients. Nephrol Dial Transplant 1994; 9(10): 1453-5.

[25] French VA, Davis JS, Sayles HS, Wu SS. Contraception and fertility awareness among women with solid organ transplants. Obstet Gynecol 2013; 122(4): 809-14.

[26] Watnick S, Rueda J. Reproduction and contraception after kidney transplantation. Curr Opin Obstet Gyn 2008; 20(3): 308-12.

[27] Tong A, Tjaden L, Howard K, Wong G, Morton R, Craig JC Quality of life of adolescent kidney transplant recipients. J Pediatr 2011; 159(4): 670-5 e2.

[28] Forhan SE, Gottlieb SL, Sternberg MR, et al. Prevalence of sexually transmitted infections among female adolescents aged 14 to 19 in the United States. Pediatrics 2009; 124(6): 1505-12.

[29] Seshadri L, George SS, Vasudevan B, Krishna S. Cervical intraepithelial neoplasia and human papilloma virus infection in renal transplant recipients. Indian J Cancer 2001; 38(2-4): 92-5.

[30] Nguyen L, McClellan RB, Chaudhuri A, et al. Conversion from tacrolimus/mycophenolic acid to tacrolimus/leflunomide to treat cutaneous warts in a series of four pediatric renal allograft recipients. Transplantation 2012; 94(5): 450-5.

[31] Primeggia J, Timpone JG, Jr., Kumar PN. Pharmacologic issues of antiretroviral agents and immunosuppressive regimens in HIVinfected solid organ transplant recipients. Infect Dis Clin North Am 2013; 27(2): 473-86

[32] Korenromp EL, Sudaryo MK, de Vlas SJ, et al. What proportion of episodes of gonorrhoea and chlamydia becomes symptomatic? Int J STD Aids 2002; 13(2): 91-101.

[33] Farley TA, Cohen DA, Elkins W. Asymptomatic sexually transmitted diseases: the case for screening. Prev Med 2003; 36(4): 502-9.

[34] Burstein GR, Lowry R, Klein JD, Santelli JS. Missed opportunities for sexually transmitted diseases, human immunodeficiency virus, and pregnancy prevention services during adolescent health supervision visits. Pediatrics 2003; 111(5 Pt 1): 996-1001.

[35] Meyers D, Wolff T, Gregory K, et al. USPSTF recommendations for STI screening. Am Fam Physician 2008; 77(6): 819-24.

[36] CDC. 2010 STD Treatment Guidelines 2010 [updated August 2012; cited 2014 July $7^{\text {th }}$ ]. Available from: http://www.cdc.gov/ STD/treatment/2010/default.htm.

[37] Newbern EC, Anschuetz GL, Eberhart MG, et al. Adolescent sexually transmitted infections and risk for subsequent HIV. Am J Public Health 2013; 103(10): 1874-81.

[38] WHO. Making Health Services Adolescent Friendly: Developing National Quality Standards for Adolescent Friendly Health Services 2012 [cited 2014 July $10^{\text {th }}$ ]. Available from: http://apps.who.int/iris/bitstream/10665/75217/1/9789241503594_e ng.pdf.

[39] Ford C, English A, Sigman G. Confidential Health Care for Adolescents: position paper for the society for adolescent medicine. J Adolesc Health 2004; 35(2): 160-7.

[40] Ford CA, Millstein SG, Halpern-Felsher BL, Irwin CE, Jr Influence of physician confidentiality assurances on adolescents' willingness to disclose information and seek future health care. A randomized controlled trial. JAMA 1997; 278(12): 1029-34.

[41] CDC. Antiretroviral Postexposure Prophylaxis After Sexual, Injection-Drug Use, or Other Nonoccupational Exposure to HIV in the United States Recommendations from the U.S Department of Health and Human Services 2005 [updated January $21^{\text {st }}$, 2005; 
cited 2014 July $7^{\text {th }}$ ]. Available from: http://aidsinfo.nih.gov/con tentfiles/NonOccupationalExposureGL.pdf

[42] Torkko KC, Gershman K, Crane LA, Hamman R, Baron A. Testing for Chlamydia and sexual history taking in adolescent females: results from a statewide survey of Colorado primary care providers. Pediatrics 2000; 106(3): E32.

[43] Hawkins JD, Catalano RF, Kosterman R, Abbott R, Hill KG. Preventing adolescent health-risk behaviors by strengthening protection during childhood. Arch Pediatr Adolesc Med 1999; 153(3): 226-34.

[44] Hill KG, Bailey JA, Hawkins JD, et al. The onset of STI diagnosis through age 30: results from the Seattle Social Development Project Intervention. Prev Sci 2014; 15 Suppl 1: S19-32.

[45] Finer LB, Philbin JM. Sexual initiation, contraceptive use, and pregnancy among young adolescents. Pediatrics 2013; 131(5): 88691.

[46] Chow KM, Law MC, Leung CB, Szeto CC, Li PK. Antibody response to hepatitis $\mathrm{B}$ vaccine in end-stage renal disease patients. Nephron Clin Pract 2006; 103(3): c89-93.

[47] Merckvaccines.com. Gardasil Product Information 2014 [cited 2014 July $7^{\text {th }}$. Available from: https://www.merckvaccines.com/ Products/Gardasil/Pages/home.

[48] Lunn A, Ravenscroft J, Watson AR. Cutaneous warts in children before and after renal transplantation. Pediatr Neurol 2010; 25(5): 941-6.

[49] American College of O, Gynecologists. ACOG Committee Opinion No. 463: Cervical cancer in adolescents: screening, evaluation, and management. Obstet gynecol 2010; 116(2 Pt 1): 469-72.

[50] Szpotanska-Sikorska M, Pietrzak B, Wielgos M. Contraceptive awareness and birth control selection in female kidney and liver transplant recipients. Contraception 2014.

[51] osephson MA, McKay DB. Women and transplantation: fertility, sexuality, pregnancy, contraception. Advances in chronic kidney disease 2013; 20(5): 433-40.

[52] Sifontis NM, Coscia LA, Constantinescu S, Lavelanet AF, Moritz MJ, Armenti VT. Pregnancy outcomes in solid organ transplant recipients with exposure to mycophenolate mofetil or sirolimus. Transplantation 2006; 82(12): 1698-702.

[53] FDA. Risk Evaluation and Mitigation Strategy (REMS) Single Shared System for Mycophenolate 2012 [updated September 2013; cited 2014 July $\left.19^{\text {th }}\right]$. Available from: http://www.fda.gov/down loads/Drugs/DrugSafety/PostmarketDrugSafetyInformationforPatie ntsandProviders/UCM321261.pdf.

[54] NAPRTCS. NAPRTCS 2010 Annual Report 2010 [cited 2014 July $\left.7^{\text {th }}\right]$. Available from: https://web.emmes.com/study/ped/annlrept/ 2010_Report.pdf.

[55] Armenti VT, Moritz MJ, Davison JM. Drug safety issues in pregnancy following transplantation and immunosuppression: effects and outcomes. Drug safety 1998; 19(3): 219-32.
[56] Transplantation EEGoR. European best practice guidelines for renal transplantation. Section IV: Long-term management of the transplant recipient. IV.10. Pregnancy in renal transplant recipients. Nephrol Dial Transplant 2002; 17 Suppl 4: 50-5.

[57] Finer LB, Zolna MR. Shifts in intended and unintended pregnancies in the United States, 2001-2008. Am J Public Health 2014; 104 Suppl 1: S43-8.

[58] Committee on Adolescent Health Care Long-Acting Reversible Contraception Working Group TACoO, Gynecologists. Committee opinion no. 539: adolescents and long-acting reversible contraception: implants and intrauterine devices. Obstet Gynecol 2012; 120(4): 983-8.

[59] Hood JE, Hogben M, Chartier M, Bolan G, Bauer H. Dua contraceptive use among adolescents and young adults: correlates and implications for condom use and sexually transmitted infection outcomes. J Fam Plann Reprod Health Care 2014; 40(3): 200-7.

[60] Hatcher RA TJ, Stewart F, et al. Contraceptive Technology. 19th ed. New York, NY: Ardent Media; 2007.

[61] Krajewski CM, Geetha D, Gomez-Lobo V. Contraceptive options for women with a history of solid-organ transplantation. Transplantation 2013; 95(10): 1183-6.

[62] Morrison CS, Sekadde-Kigondu C, Sinei SK, Weiner DH, Kwok C, Kokonya D. Is the intrauterine device appropriate contraception for HIV-1-infected women? BJOG-Int J Obstet Gy 2001; 108(8): 78490.

[63] Bitzer J. Oral contraceptives in adolescent women. J Clin Endocrinol Metab 2013; 27(1): 77-89.

[64] Paulen ME, Folger SG, Curtis KM, Jamieson DJ. Contraceptive use among solid organ transplant patients: a systematic review. Contraception 2010; 82(1): 102-12.

[65] Pietrzak B, Bobrowska K, Jabiry-Zieniewicz Z, et al. Oral and transdermal hormonal contraception in women after kidney transplantation. Transplant Proc 2007; 39(9): 2759-62.

[66] Paternoster DM, Riboni F, Bertolino M, et al. The contraceptive vaginal ring in women with renal and liver transplantation: analysis of preliminary results. Transplant Proc 2010; 42(4): 1162-5.

[67] Bigrigg A, Evans M, Gbolade B, et al. Depo Provera. Position paper on clinical use, effectiveness and side effects. Brit J Fam Plan 1999; 25(2): 69-76.

[68] Guazzelli CA, de Queiroz FT, Barbieri M, Torloni MR, de Araujo FF. Etonogestrel implant in adolescents: evaluation of clinical aspects. Contraception 2011; 83(4): 336-9.

[69] FDA. FDA approves Plan B One-Step emergency contraceptive for use without a prescription for all women of child-bearing potential 2013 [updated June 20th; cited 2014 July $10^{\text {th }}$. Available from: http://www.fda.gov/newsevents/newsroom/pressannouncements/uc m358082.htm 